\title{
Aspectos quirúrgicos de la infección urinaria
}

DRES: CESAR IZZO *, FRANCISCO OSSANDON * $Y$ ANTONIO MOREY ${ }^{*}$.

La Infección Urinatia del niño, es para la urología infantil, uno de los sindromes que más frecuentemente nos lleva a descubrir una anomalía de la vía urinaria, muchas veces corregible quirúrgicamente.

Desde el punto de vista urológico, la infección urinaria está condicionada por toda causa anatómica o funcional que altera el flujo urinario, ya sea retardándolo o manteniendo un residuo, susceptible de infectarse. Desde este punto de vista podemos dividir estas malformaciones en 2 tipos:

1.- De causa Mecánica obstructiva.

2.-De causa Funcional secundaria a una alteración fisiológica del vaciamiento urinario.

$\mathrm{Si}$ dividimos el aparato urinario en un sistema alto, que incluye rinón, cálices, pelvis y ureteres, y un sistema bajo de vejiga y uretra, podemos clasificar las malformaciones en altas y bajas.

Siguiendo esta clasificación queremos presentarles algunos casos tratados en el Departamento de Nefrourología del Hospital Luis Calvo Mackenna.

En la tabla 1 mostramos las causas mecánicas de obstrueción en el aparato urinario alto. De ellas la obstrucción pielo-ureteral (hidronefrosis pura de los ingleses) es la más frecuente (33 casos op. en los últimos 10 años). Esta anomalía se acompaña de infección urinaria en el $50 \%$ de los casos. La segunda en frecuencia es la Litiasis (24 casos en 25 años) que se acompaña en un $82 \%$ de infección urinaria.

La estenosis ureteral yuxta vesical es menos frecuente, así como el ureterocele (tenemos 11 casos) que se ye en enfermos con riñon doble y obstrucción de la desembocadura vesical del ureter correspondiente al riñón superior. El uretero-

\footnotetext{
" Depto. de Nefrourología. Hospital L. Calvo Mackenna.
}

\author{
TABLA No 1
}

CAUSAS MECANICAS OBSTRUCTIVAS DE ESTASIA E INFECCION EN APARATO URINARIO ALTO

1.- Estenosis caliciaria segmentaria.

2.-Obstrucción Pielo-ureteral (Hidronefrosis).

a) Atresia o Estenosis.

b) Inserción alta de ureter con adherencias y acodaduras.

c) Vaso aberrante.

3.-Litiasis del Aparato Pieloureteral.

4.-Estenosis Ureteral Baja Yuxta Vesical.

5.-Ureterocele (Obstrucción de desembocadura del ureter ).

TABLA No 2

CAUSAS MECANICAS DE OBSTRUCCION EN APA. RATO URINARIO BAJO

1.-Ureterocele Prolapsante.

2.-Pólipos Vesicales (raros).

3.- Valvas Congénitas de Uretra posterior.

4.-Litiasis Uretral o Vesical.

5.-Diverticulo Uretral.

6. - Estenosis Meatal.

cele, al resecarse quirúrgicamente suele quedar con reflujo y es necesario tratarlo posteriormente.

En la tabla 2 mostramos las causas mecánicas de obstrucción baja. Las valvas de uretra posterior aunque poco frecuente (4 casos) son la causa más frecucnte de insuficiencia renal y vejiga palpable en el recién nacido hombre. Su tratamiento quirúrgico se acompaña de una total regresión de la sintomatología y alteraciones radiológicas. 
Las obstrucciones funcionales altas se detallan en la tabla 3.

El megaureter congénito corresponde a una falla de la motilidad del ureter por alteración neuro-muscular, determinando una falta de propulsión de la orina y dilatación secundaria.

El reflejo vesico-ureteral es la causa más frecuente de infección urinaria persistente o recidivante en el niño y lo vemos cada vez con mayor frecuencia. Nuestro departamento está operando todos aquellos reflujos que persisten con infección, después de un tratamiento médico de más de 6 meses. En aquellos reflujos que persisten sin infección, o que nunca han tenido bacteriuria, la indicación quirúrgica dependerá del compromiso renal en sucesivas pielografías o de su estudio funcional. Reflujos que tengan pruebas funcionales alteradas (clearance de creatinina, prueba de concentración) o signos radiológicos de pielonefritis o hidrocalicosis deben ser tratados quirúrgicamente, mediante el neoimplante de ureter en vejiga. Es preferible evitar la operación en los menores de 2 años por dificultades técnicas y porque puede mejorar el reflujo con el crecimiento. Es importante controlar periódicamente estos niños hasta la edad escolar, en estrecha colaboración con el pediatra y cirujato.

En cuanto a las causas funcionales (Tabla 4) la vejiga neurogénica por espina bifida es la más frecuente y la que mayor problema nos da. Debido a que las técnicas quirúrgicas para mejorar la incontinencia son de bajo rendimiento, nosotros preferimos el tratamiento conservador. En los casos en que el esfinter externo interfiera con buen vaciamiento hay que ir a la esfinterotomía. En vejigas hipertónicas puede asociarse reflujo, que puede ceder al actuar sobre el cuello vesical, facilitando el vaciamiento. En caso de infección persistente con año renal progresivo debe recurrirse a la operación de Bricker, derivando ureteres a un asa aislada de ileon y ésta a la piel.
T A B A No 3

CAUSAS FUNCIONALES DE ESTASIA EN APARATO URINARIO ALTO

1.- Megaureter Congénito sir o con Reflujo.

2.- Reflujo Vesico Ureteral con o sin Megaureter Secundario.

TA B L A No 4

CAUSAS FUNCIONALES DE ESTASIA EN APARATO URINARIO BAJO

1.- Vejiga Neurogénica.

2.-Divertículo Vesical.

3.- Fístuja Recto vesical o rectouretral en Imperfoperforación Anal.

Hemos revisado algo de puestra experiencia en lo que es el problema de infección urinaria y cirugía. Queremos insistir que el manejo adecuado de este problema requiere la colaboración mutua de nefrólogos y urólogos.

Hemos revisado someramente las causas de obstrucción mecánica y funcional del aparato urinario que segúu nuestra experiencia son las más frecuentes.

El diagnóstico y manejo de estos pacientes es muy variado ya que lo habitual es que se reúnan varias condiciones (obstrucción más litiasis) (obstrucción más reflujo) (Duplicación más reflujo), etc. y para su correcta interpretación y decisión terapéutica se requiere el concurso de pediatras, radiólogos y cirujanos que posean experiencia adecuada y que colaboran estrechamente. 